\title{
Research on Strategies for Tourism Development of Changbai Mountain North Scenic Spot*
}

\author{
Liguang Zhao \\ School of Taxation \\ Jilin University of Finance and Economics \\ Changchun, China 130117
}

\author{
Mingju Liu \\ Yatai School of Business Administration \\ Jilin University of Finance and Economics \\ Changchun, China 130117
}

\author{
Xin Zhao \\ Yatai School of Business Administration \\ Jilin University of Finance and Economics \\ Changchun, China 130117
}

\begin{abstract}
With development of economy, travelling has become a part of people's life. As a result, tourism also becomes one of the most powerful industries with largest scale in global economy. Changbai Mountain North Scenic Spot is one of the eight scenic areas and the important scenic spot in Jilin Province, so how to develop the tourism in scenic area becomes an important issue. Starting from the concept and characteristics of sustainable development, this paper points out the problems exist in the process of developing tourism in North Scenic Spot and proposes corresponding solutions and strategies based on the analysis of general situation of Changbai Mountain North Scenic Spot.
\end{abstract}

Keywords-Changbai Mountain North Scenic Spot; travelling; sustainable development

\section{INTRODUCTION}

Under the general background of people's increasingly enhanced living standard, tourism has become an important part of people in their leisure time. Traveling is a kind of selfrealization activity for people to seek joyful and happy life. It has become an important and indispensable part of modern social life just like the grain for human to survive. As the tertiary industry in modern society, tourism has become one of important industries to increase national GDP, and the promotion of tourism sustainable development becomes the first important task in the industry. Changbai Mountain is one of China's ten famous mountains, one of the eight scenic spots in Jilin, and the important scenic spot of Jilin Province, so the development of tourism of scenic spot is an issue worthy of studying.

*Fund Project: National natural science fund project (project No.: 41401146); project of science \& technology development program of Jilin Province (20150204040NY). Project of Jilin Education Bureau (JJKH20170140SK).

\section{OVERVIEW OF SUSTAINABLE DEVELOPMENT}

\section{A. Connotation of Sustainable Development}

Sustainable development refers to development mode not influencing the demand for current society development while it can promote the society development in the future, not affecting the benefits of future generations while it can satisfy modern people's benefits. Sustainable development is the development established under common stability of various factors of the society. Various elements of the society not being damaged shall be satisfied, to obtain the sustainable development simultaneously. Sustainable development should meet the purpose of development process and protect the environment people relied to live not to be damaged, to offer better environment and development to the future generations. Sustainable development is closely related to environmental protection, but cannot be replaced by the so-called environmental protection, which is an important aspect of sustainable development. Sustainable development reflects in three aspects, namely sustainable development in terms of economy, sustainable development in terms of ecology, and sustainable development in terms of society. These three aspects promote each other and influence each other, reflecting as people pay attention to economic efficiency in development, focus on ecological harmony and pursue social fairness, in order to obtain the all-round development.

\section{B. Characteristics of Sustainable Development}

1) Sustainability: Sustainable development is the new development mode that human pursuit. It emphasizes the common development of economy, ecology and society, to protect the environment that human relied to live while promoting human's economic development, and to guarantee the fairness and justice of the society. The impetus and objective of sustainable development is to keep human in a long-lasting development state under the mutual promotion 
and influence of these three aspects, so that human may develop in more comprehensive way.

2) Fairness: Fairness includes three aspects. The first is the fairness among people of the same generation: as for the fairness of living quality among people of the same age group, there is no sustainable development under the status of relevant wide disparity of wealth; the second is the fairness of distributing limited resources: reasonable distribution of the resources existing in the society mainly reflects that different countries can distribute the resources available in the world in a reasonable and fair way. The third is the fairness between generations, or the fairness toward next generation: people in the contemporary era shall not, just for their own private interests, waste resources wantonly with the result that the ecological resources for the next generation are so little that they are unable to live and develop well.

3) Commonness: The human society has common development target and one earth. Putting forward the sustainable development strategy is not just the behavior of one region or a country, but the common behavior and obligation of people worldwide. It is our common goal to promote sustainable development in the world.

\section{BASIC CONDITION OF CHANGBAI MOUNTAIN NORTH SCENIC SPOT}

"One mountain has four seasons, while a distance of ten thousand miles does not share the same weather" refers to the beautiful Changbai Mountain. Changbai Mountain was elected as national 5A scenic spot, one of eight scenic areas of Jilin. Changbai Mountain has different names in different period of time. It was called ... as early as Zhou and Qin dynasties, Buxian Mountain in the Warring period of Spring and Autumn, Yutai Mountain in the Northern Dynasties, Taibai Mountain in Sui Dynasty, and Changbai Mountain in Liao and Jin Dynasties. Changbai Mountain boasts to have abundant natural and cultural landscapes. According to the almanac, Changbai Mountain North Scenic Spot has 1500-2500 species of wild animals.

\section{A. Natural Tourism Resources}

As one of the ten famous mountains in China, Changbai Mountain boasts to have wonderful and colorful natural resources. The beauty of Changbai Mountain lies in majestic and magnificent natural landscape and the snow in winter. Changbai Mountain has various unique landscape belts: mix forest of conifer and broadleaf tree at the height of 500-1000 meters, the trees are mainly Korean pine, larch and bark of the cork tree; the conifer - broadleaf tree belt at the height of 1000 - 1700 meters, the trees are mainly Korean pine, dragon spruce, fir; YueHuaLin belt at the height of 1700-2000 meters, the trees are mainly YueHuaLin; the Alpine tundra belt is located at the height over 2000 meters, and the vegetation are mostly the herbaceous lichen, moss. The Heavenly pond on Changbai Mountain is surrounded by 16 peaks with fantastic forms, including Baishan Peak, Tianwen Peak, Yuzhu Peak, Huagai Peak, Zhipan Peak, Longmen Peak and so on. In addition, Changbai Mountain North Scenic Spot has 12 landscapes, including Holy Beast and Heavenly Pond, Golden Cicada on
Peak, Ice Valley and Conyon, Longyan Hot Spring, Running River Underground, Green Water and Deep Pond, Small Heavenly Pond, Icy Water and Cold Spring, Floating Stone Forest, Underground Forest and so on. Large area of virgin forest is preserved in Changbai Mountain North Scenic Spot with up to 1242 species of plants and more than 550 species of animals, such as Korean pine, dragon spruce, northeast China ash, and beauty pine etc. Changbai Mountain North Scenic Spot area also has about 80 species of wild herbs, such as edible tender leaves of brakes and thorny tender leaves.

\section{B. Cultural Tourism Resources}

Viewing from the perspective of historical and cultural resources, Changbai Mountain has a long cultural history, and emperors and kings of various dynasties pay great attention to this. The emperors of Jin, Yuan and Qing Dynasties even regard Changbai Mountain as their birthplace, and praise Changbai Mountain highly as the holy mountain. North Scenic Spot has graceful natural environment and extraordinary splendor scene with unique historical ruins of various dynasties to offer sacrifices to heaven and earth, and there is relevant detail record in historical records. Therefore, it is of extremely high historical cultural value. Viewing from the cultural resources of minorities, Changbai Mountain area is the region for national minorities (Manchu nationality and Korean nationality in China) to settle with the unique national culture and folk customs still retained here up to now.

\section{ANALYSIS OF PROBLEMS EXISTING IN THE}

\section{SUSTAINABLE DEVELOPMENT OF TOURISM IN CHANGBAI} MOUNTAIN NORTH SCENIC SPOT

With the rapid development of tourism, scenic spots neglect the protection of ecological environment and sustainable development of scenic spot while pursuing maximum economic benefits. The problems of damage to ecological environment and cultural landscape resulted by this phenomenon are more and more serious. Many problems also exist in the tourism development of Changbai Mountain North Scenic Spot.

\section{A. Inconvenient Traffic}

As for the tourists, the convenience of traffic to scenic spot becomes an important factor for them to choose scenic spot in their leisure time. Though Changbai Mountain North Scenic Spot is well known worldwide, the traffic to scenic spot is extremely inconvenient. At present, the traffic of Changbai Mountain North Scenic Spot is divided into the following three categories: first, get to the scenic spot by train. To go to Changbai Mountain North Scenic Spot, tourists can get off from Erdao Baihe Station and Dunhua Station. The first is to get to Erdao Baihe Station which is the nearest to Changbai Mountain North Scenic Spot, and then tourists still need to take a coach to go to Changbai Mountain North Scenic Spot. The second is Dunhua Station, after tourists have arrived at this station, and they still need to take a coach to the North Scenic Spot via Erdao Baihe Station, which is wastes time and strength. Second, take a coach to get to the scenic spot. There are two ways to go to Changbai Mountain North Scenic Spot: the first is to take a chartered bus to Changbai Mountain North 
Scenic Spot after arriving Erdao Baihe Station; the second is to take a nonstop bus to Changbai Mountain North Scenic Spot from west bus stop of Yanji, but it is time-consuming. Third, to get to the scenic area by air, tourists who choose to fly to the scenic area need to get to Changbai Mountain Airport, and then take a 4-hour airport bus to Changbai Mountain. The planes from other places of China can only arrive in the several airports of Changchun, Yanji and Tonghua near the North Scenic Spot, and then change bus for Changbai Mountain North Scenic Spot. The nearest one is Yanji Ariport, but it still needs 3-4 hours to get to Changbai Mountain North Scenic Spot. Based on these conditions, we analyze that it will cost tourists a long time to get to Changbai Mountain, and tourists coming afar need even more time to take bus with less time to go sightseeing, which has impacted tourists' satisfaction toward the scenic spot.

\section{B. Simple Tourism Product}

In recent years, cultural tourism is increasingly expanded. Changbai Mountain North Scenic Spot has abundant natural resources, for example, Heavenly Pond, Changbai Mountain Waterfall and so on. Changbai Mountain is the highest mountain in northeast China, and most of the scenic spots on it are for appreciating. As the birthplace of Manchu nationality, Changbai Mountain has quite few items of folk custom and entertainment. Tourists can only appreciate the beautiful scenery of Changbai Mountain in the scenic area, but cannot integrate with nature by experiencing in it personally.

\section{Insufficient Capacity of Scenic Spot}

The environmental bearing capacity of scenic spot is the key problem influencing sustainable development of the scenic spot. Insufficient capacity of the scenic spot influences not only the environment of the scenic spot, but also tourists' satisfaction. Large amount of tourists flowing into the scenic area will produce unnecessary wastes and garbage. Too many tourists in one scenic spot will damage the effective resources in the scenic spot, which is unfavorable for the sustainable development of scenic spot. With the rapid development of society and the improvement of human's living standard, there are more and tourists visiting Changbai Mountain North Scenic Spot, while the problem of overload in scenic spot emerges gradually with the increase in tourists. Too many tourists in Changbai Mountain North Scenic Spot each day will bring about many passive influences while creating huge economic benefits for the scenic spot. The scenic spot will be overcrowded due to too many tourists in it. As a result, tourists cannot appreciate very well, reducing their satisfaction toward the scenic area. In addition, too many tourists and overcrowded scenic spot will cause safety problems of tourists and impact the environment of scenic area. Changbai Mountain North Scenic Spot is one of the ten famous mountains in China, the achievement of sustainable development of Changbai Mountain North Scenic Spot and how to solve the problem of scenic spot capacity is the priority among priorities.

\section{Uncompleted Infrastructure in Scenic Spot}

The infrastructure within scenic spot is one of the important links influencing tourists' impression toward the scenic spot. Improving the infrastructure within scenic spot is the first thing to be focused on to achieve sustainable development of Changbai Mountain North Scenic Spot. Changbai Mountain North Scenic Spot is developed quite early; therefore, many problems exist in the infrastructure within it at present. The stools for tourists to have a rest are too obsolete; it is short of toilets, sightseeing bus within the scenic spot and restaurants; the prices of foods are much too high. Changbai Mountain North Scenic Spot is a 5A level scenic spot, but the service quality of the staff in the scenic spot does not conform to the regulations of scenic spot, as the personnel has quite low educational level and service quality, being unable to solve the problems raised by tourists. All of these problems will reduce tourists' satisfaction, which is unfavorable for the implementation of sustainable development strategy of Changbai Mountain North Scenic Spot.

\section{E. Weak Awareness of Tourists to Protect Environment}

Tourists are the important part of tourism environment. According to the statistics, more than ten thousands tourists enter into Changbai Mountain North Scenic Spot each day. Therefore, tourists have become the key factor influencing the sustainable development of Changbai Mountain North Scenic Spot. Many bad phenomena appear due to different education degree and quality of the tourists within the scenic spot, such as relieving oneself at will, throwing about rubbish everywhere, writing and painting on public items and so on. These bad behaviors of tourists have shortened the age limit of resources of Changbai Mountain North Scenic Spot and damaged the sustainable development of Changbai Mountain North Scenic Spot.

\section{SUSTAINABLE DEVELOPMENT STRATEGY FOR THE TOURISM OF CHANGBAI MOUNTAIN NORTH SCENIC SPOT}

As the international 5A level scenic spot, Changbai Mountain North Scenic Spot boasts to have abundant natural resources. Nevertheless, many problems still exist in the scenic spot. To promote the sustainable development of Changbai Mountain North Scenic Spot, it is particularly important to solve the existing problems in North Scenic Spot. The following strategies are proposed to solve the existing problems.

\section{A. To Add the Tourism Line Planning}

It is important to keep pace with the pace of the times in order to achieve sustainable development of the scenic spot based on existing resources of Changbai Mountain North Scenic Spot. According to the statistics almanac, the "Ten Years' Appointment" of Zhang Qiling, the main figure in the book of "The Lost Tomb", planned by the scenic spot in 2015, promote the number of tourists entering into Changbai Mountain Scenic Spot rise sharply. It can be known from this phenomenon that Changbai Mountain North Scenic Spot should not stick to the old ideology, but to add new type of tourism line following the hot spot in society. Add the tourism point and program according to the hot topic in contemporary era, to increase the number of tourists of Changbai Mountain North Scenic Spot, and promote the economic sustainable development of Changbai Mountain North Scenic Spot. 


\section{B. To Add the Emerging Tourism Product}

In recent years, cultural landscapes account for a larger and larger proportion in the mind of the tourists. Tourists expect to experience the local folk customs while viewing the peculiar and beautiful landscapes. Changbai Mountain possesses excellent natural resources, and it is the birthplace of Manchu nationality, rendering it many advantages. Therefore, it should develop new type of tourism products step by step, for example, adding the national programs, tasting the characteristic snacks of Manchu nationality, so that tourists can learn about the folk culture and custom of northeast China step by step after enjoying the majestic and magnificent mountains and rivers. Tourists are very curious about the mysterious Changbai Mountain, so the exploration project can be added, to trigger the tourists' sense organ, enabling tourists to integrate with Changbai Mountain North Scenic Spot. Moreover, Changbai Mountain Museum can also be established to explain the formation of many unique landscapes in Changbai Mountain North Scenic Spot, enabling tourists to learn more about Changbai Mountain and increase their geographical knowledge while appreciating it. In this way, tourists' satisfaction towards the scenic spot can be enhanced, to promote the economic sustainable development of scenic spot without damaging ecological resources of the scenic spot.

\section{To Improve the Management of Tourists in Scenic Spot}

Tourists form an important part of the tourism environment of Changbai Mountain North Scenic Spot. As for the weak awareness of tourists to protect the environment, scenic spot should take certain measures, for example, place an advertising logo at each scenic spot in the scenic area, to remind tourists of protecting the scenic area environment; set garbage cans at certain distance, to remind tourists of environmental protection while keeping safe. As for those tourists of low quality, scenic area should warn the tourist by imposing a fine. Protection of scenic spot's environment is not only the responsibilities of the staff in the scenic area, but the responsibility and obligation of the tourists themselves. Only in this way, can the limited resources in the scenic area be protected from damage, enabling later generations to appreciate the magnificent and beautiful scenery of Changbai Mountain.

\section{To Regulate Distribution of Tourists}

Environment is an essential item of the sustainable development of the scenic area. Changbai Mountain North Scenic Spot is of innate advantages, yet it should control the tourism environment and tourists' experience in later period, thus the sustainable development of Changbai Mountain North Scenic Spot can be realized. In order to make Changbai Mountain North Scenic Spot develop sustainably, it is important to regulate the distribution of time and space of tourists in scenic spot. Each scenic spot has its own characteristics with different visitor bearing capacity from other scenic spots. In recent years, however, the number of tourists entering into Changbai Mountain North Scenic Spot goes up sharply. In the recent two years, Changbai Mountain North Scenic Spot was overcrowded due to the Ten Years' Appointment of Zhang Qiling in The Lost Tomb while improving its economic development. Though the works offers
Changbai Mountain with good reputation, the tourist bearing capacity of Changbai Mountain North Scenic Spot is limited. Too many people entering into the scenic spot each day results in many hidden troubles in the scenic spot. Under such circumstances, Changbai Mountain North Scenic Spot should adopt corresponding policies. According to statistics, during the period of 10 am to $1 \mathrm{pm}$ each day, there are too many people entering into Changbai Mountain North Scenic Spot. Therefore, relevant personnel shall control the number of people entering into the scenic area, to ensure the number of people entering into Changbai Mountain North Scenic Spot not exceeding the tourist bearing capacity of this scenic spot and to sustain the environmental bearing capacity of the scenic spot. Second, the Heavenly Pond in Changbai Mountain North Scenic Spot is well known worldwide, many tourists want to appreciate the Heavenly Pond coming afar. Changbai Mountain North Scenic Spot should control the number of people in the scenic spot each day, regulate the quantity of tourists. Such measures will maintain the quantity of tourists in Changbai Mountain North Scenic Spot while guarding the safety the tourists while they are going sightseeing, making the resources of scenic spot be developed sustainably.

\section{E. To Strengthen Infrastructure Construction}

The infrastructure of the scenic spot is one of the factors determining tourists' satisfaction towards the scenic spot. Changbai Mountain North Scenic Spot was developed quite early; therefore, the facilities are old and the working staff of the scenic spot offer services with low quality. With respect to the obsolete facilities in the scenic spot, a series of measures should be taken. For instance, increase the number of garbage cans, replace the public facilities in the rest area of the scenic spot regularly, and add the tourist bus of the scenic spot. As for the low-quality service personnel within the scenic area, the training about service wording and etiquette in the scenic area should be offered at regular intervals, for example, the unique hand gestures within the scenic area, and extend greetings to the tourists actively and so on. The scenic spot has unique characteristics while satisfying the tourists; therefore, the tourists may be attracted by mountains and rivers, as well as the distinctive etiquette culture of the scenic spot. In addition, the popularity of the scenic spot will be improved in this way. As a result, we should improve the professional accomplishment and service etiquette knowledge of the service personnel and enhance tourists' satisfaction toward Changbai Mountain North Scenic Spot, so as to promote the sustainable development of Changbai Mountain North Scenic Spot.

\section{CONCLUSION}

Sustainable development of Changbai Mountain North Scenic Spot is particularly important as it is a national 5A level scenic spot, and one of ten famous mountains in northwest China. Protect the existing resources of the scenic spot while achieving economic sustainable development of the scenic spot, so that the resources of the scenic spot may be developed and utilized reasonably and the descendants may also appreciate the miracle and beautiful Changbai Mountain. By analyzing the problems of tourism development of Changbai Mountain North Scenic Spot, the development strategy of Changbai Mountain in the future is proposed, to provide 
guarantee for the sustainable development of Changbai Mountain North Scenic Spot in five aspects, namely route design, product development, control of environmental capacity, tourist management and infrastructure.

\section{REFERENCES}

[1] Yingnan Liu. Study on Sustainable Development of Changbai Mountain Tourism [D]. Changchun University of Technology, 2012. 刘英男.长白 山旅游业的可持续发展研究[D].长春工业大学, 2012

[2] Mingju Liu, et al. Study on Sustainable Development of Changbai Mountain North Scenic Spot [J] .Taxation and Economy, 2015(5). 刘明 菊等.长白山北景区旅游可持续发展研究 [J]. 税务与经济, 2015 (5)

[3] MingjuLiu, et al. Research on Current Situation of Tourism in Changbai Mountain North Scenic Spot and Countermeasures [J]. Journal of Green Science and Technology, 2015(1). 刘明菊等.长白山北景区旅游发展 现状及对策研究[J].绿色科技, 2015(1).

[4] Mingju Liu, Fang Yuan. Reflections on Tourism Resources Research [J]. Taxation and Economy, 2016（1）刘明菊, 袁方.关于旅游资源研究 的几点思考 [J]. 税务与经济, 2016 (1)

[5] Na Yang. Research on Tourism Sustainable Development in Jilin Province [D]. Changchun University of Technology, 2012. 杨娜.吉林 省旅游业可持续发展研究[D].长春工业大学, 2012 